Бажак О.В., Трофименко І.В., Бойко А.Д.

\title{
СИНТЕЗ МОДЕЛІ ТА АЛГОРИТМІВ ПРОЦЕСУ КЕРУВАННЯ РУХОМ СУДНА
}

В статті розроблена модель систем керування судном. Особливістю даної моделі $\epsilon$ взаємозв'язок суднових навігачійних пристроїв з енергетичними системами судна. Використання даної моделі дозволяє вивчити та дослідити якісні показники судна та виявити залежності впливу їх характеристик на якість керування судна.

Також у статті наведено алгоритмічні рішення системи керування судном та висвітлюються позитивні та негативні властивості їх використання.

Для дослідження руху судна як правило застосовуються динамічні моделі 3 оптимізацією керуючих впливів. При цзьому, у якості моделі динамічі просторового стану можна використовувати модель Пуанкор, а для часткового вирімення систем рівнянь даних моделей можна використовувати статистичні методи. Це пов'язано з тим щуо, аналітичні рішення знаходяться тільки в небагатьох випадках.

Таким чином, виникає необхідність розроблення нових моделей руху судна по заданому маршруту та його керування в складній динамічній обстановиі.

Тому метою даної статті $\epsilon$ розробка моделі системи керування судном 3 можливістю висвітлення логічних зв'язків для підвищення ефективності судноводіння під час його експлуатації в складних умовах для забезпечення безпеки управління судна.

Ключові слова: автоматизована система керування, навігащійні пристрої, судноводіння, керування судном, енергетичні системи.

Вступ. Ефективне використання сучасних морських транспортних засобів пов'язано із використанням завдання керування судном за заданим оптимальним маршрутом руху забезпечуючи навігаційну безпеку судноводіння в заданому регіоні [1]. При цьому на судно впливають множина факторів, як зовнішнього впливу, так i внутрішніх збурень, які не мають адекватного математичного опису в повному обсязі $[1,2]$.

Тому застосування традиційних підходів стає малоефективним. У зв'язку з цим, на сьогоднішній день актуально $є$ розроблення математичних моделіей руху судна 3 оцінкою ефективності їх дії $[1,3]$.

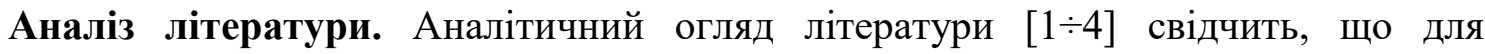
дослідження показників якості, вивчення характеристик i аналіз граничних можливостей будь-якої складної технічної системи застосовуються математичні моделі. При цьому, моделювання повинно відповідати досліджуваного процесу управління судном зі збереженням структури, а також із взаємодією між різними елементами системи. Крім цього, необхідно враховувати як зовнішні впливи так і ті, внутрішні чинники, які впливають на судноводіння.

На сьогоднішній день існуючий методичний апарат не можливо застосувати для вивчення в повному обсязі, так як він не пристосований до дослідження нових структур і елементів системи керування судном, а також до пошуку нових рішень при вивченні характеристик суднових пристроїв i приладів. Це пов'язано 3 одного боку 3 ускладненням описування процесів, що протікають, а з іншого боку це детальний опис в математичної моделі процесів керування судном при дослідженні ефективного розрахунку оптимальних режимів функціонування. 
Тому для дослідження руху судна необхідно застосовувати динамічні моделі 3 оптимізацією керуючих впливів [5]. При цьому, модель динаміка просторового стану можна використовувати модель Пуанкоре [6], а до часткового вирішення систем рівнянь даних моделей можна використовувати статистичні методи [5]. Це пов'язано 3 тим що, аналітичні рішення знаходяться тільки в небагатьох приватних випадках.

Таким чином, виникає необхідність розробки нових моделей руху судна по заданому маршруту та його керування в складній динамічній обстановці.

Мета статті. Тому метою даної статті $є$ розробка моделі системи керування судном 3 можливістю висвітлення логічних зв'язків для підвищення ефективності судноводіння під час його експлуатації в складних умовах для забезпечення безпеки управління судна.

Виклад основного матеріалу. Основою для розробки моделі $є$ дослідження властивостей системи за допомогою побудови штучно створеного фізичного або абстрактного образу реального об'єкта $[5,6,7]$. В даному випадку побудова структури моделі і використання методів математичного опису фізичних процесів істотно визначають якісні характеристики і досліджуваної технічної системи і процесів, що протікають, забезпечуючи можливість детального вивчення, а також аналізу даних їх надійності, прогнозу відмов і аварійних ситуацій при виконанні завдання судноводіння. 3 огляду на вищевикладене при побудові моделі, необхідно враховувати і описати структурні зв'язки елементів моделі для можливості вирішення поставленого завдання - побудувати маршрут оптимального судноводіння [6, 7]. Крім цього, модель необхідна для підтвердження висунутих гіпотез, які пов'язані з побудовою суднових систем i дослідження процесів, що протікають 3 навігаційно-інформаційним комплексом і енергетичними системами судна, а також для вирішення ряду штурманських завдань 3 безпеки судноводіння і якісного навігаційного забезпечення в заданій акваторії $[5,7]$. Тому, в даному випадку необхідно побудувати модель в якій повинні входити ті елементи, які безпосередньо впливають на якість роботи функціональних енергетичних вузлів та пристроїв судна та суднові навігаційні пристрої. Остаточний підсумок, пов'язаний 3 якістю функціонування судна повинно здійснюватися на основі визначення місцеположення та аналізу показників якості проходу судна за даними навігаційних параметрів з урахуванням метеорологічного впливу з урахуванням всіх умов обмежень.

На рис. 1 представлена структурна схема моделі та їі інформаційні зв’язки для дослідження характеристик енергетичних пристроїв (частина двигунів) в залежності від зміни властивостей морської поверхні і надання керуючих впливів від навігаційноінформаційного комплексу через автоматизовані системи $[1,3,4]$. В даному випадку автоматизовані системи керування енергетичними установками також підвержені впливу, який необхідно враховувати при досліджені, а вхідними даними для моделі $є$ параметри (або характеристики) іï елементів і схема сполучення їх у відповідності структури.

Запропонована модель поділяється на три основні частини, які можливо охарактеризувати як $[1,2,5,7]$ :

- ввідна частина - введення вихідних даних, що стосуються судна (енергетичні та навігаційні системи) та водяться метеоумови в яких перебуває судно;

- розрахункова частина моделі - здійснюються основні розрахунки та обчислювання модулів;

- виведення отриманих результатів - оцінюються отримані результати та порівнюються з відомими даними.

Основними структурними елементами моделі $\epsilon$ моделі: модуль судна визначаються основні тактико-технічні характеристики судна, енерго-конструктивних систем, двигунів, автоматизованих систем керування судном та навігаційно- 
інформаційного комплексу; модуль метеорологічних даних про стан метеорологічних умов функціонування судна та стан морської поверхні; модуль розрахунку впливу морської поверхні; модуль розрахунку умов експлуатації та застосування суднових систем; модуль розрахунку міста розташування судна; модуль розрахунку руху по заданому маршруту; модуль розрахунку впливу морської поверхні та метеоумов на суднові навігаційні пристрої.

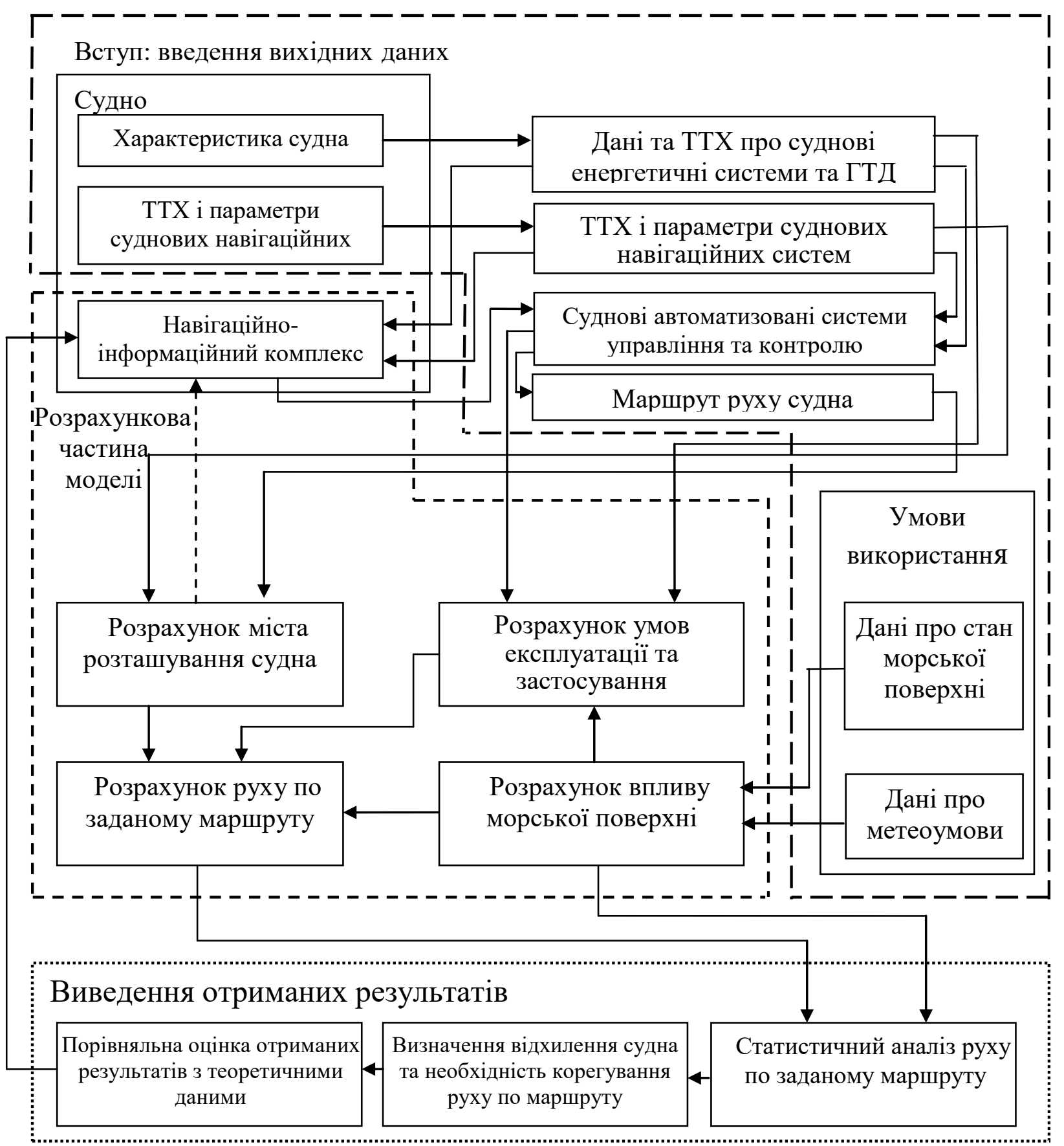

Рисунок 1 - Структурно-інформаційна схема імітаційної модели керування рухом судна

Крім описаних вище модулів використовуються модулі що пов'язані з аналізом отриманих результатів та оцінювання відхилення судна від заданого маршруту (модулі пов'язані з проведенням статистичного аналізу метеорологічних даних і їх впливу на маршрут руху судна, а також модуль в якому проводяться порівняльні характеристики отриманих результатів з теоретичними даними) на основі яких виводяться дані. 
Розкриємо деякі особливості модулів i опишемо обмеження проведених досліджень.

1. В моделі судна основним є визначення тактико-технічних характеристик судна, параметрів роботи енергетичних систем, експлуатаційні характеристики судових силових установок, данні про стан автоматизованих систем керування судном та навігаційно-інформаційного комплексу. В даному випадку автоматизовані системи керування судном незалежно від складу та конкретних пристроїв керування визначають основні етапи керування судном та включають $[3,5]$ : датчики що надають навігаційну інформацію про стан та містоположення судна для оцінки конкретної ситуації; пристрої обробки для оцінки текучого стану щодо напрацювання керуючого впливу відповідного закону керування; а також засоби відображення.

2. В основу модуля метеорологічних даних надається інформація про стан метеорологічних умов функціонування судна та стан морської поверхні. В даному випадку необхідно пам'ятати, що хвилювання моря та метеорологічних умов істотно впливають не тільки на склад конструкції судна, але і складові системи керування судна, а також на суднові силові пристрої.

3. Так як морська поверхня має складний фізичний опис, то в модулі можливо для використовувати процес впливу характеризувати як детермінований $[2,6]$, а також при необхідності використовувати динамічні розрахунки, що приводить до необхідності точного прогнозування характеристик впливу на морській транспорт. Тому застосовується модуль розрахунку впливу моря на судно на основі як статистичних так і динамічних складових $[1,7]$. Так як морська поверхня залежить від багатьох різних природних факторів, то вплив на судно та керування ним залежить від різних сил та керуючих впливів. Такими природними факторами, є: швидкість і напрям вітру, а також кут і напрямок брижі хвилі та інші.

4. Крім цього, хвилювання морської поверхні впливає умов експлуатації судна тому попередній моделювання впливають на модуль розрахунку умов експлуатації та застосування суднових систем. В даному випадку особливості експлуатації судна та безпосередньо судноводіння складається з надання даних навігаційної інформації та використання енергетичних систем керування судном під час руху.

5. Для найкращого прогнозування характеристик руху судна по курсу слід взяти до уваги статистичні дані модуля розрахунку руху по заданому маршруту відповідно до опису в детермінованих умовах [3,7]. Також необхідно в моделі враховувати вплив морського хвилювання водної поверхні що також має мінливу і складну структуру та властивості. При цьому, природні фактори, надають найбільш сильний вплив на якість судноводіння [7]. Це дає можливість дослідити особливості керуванням судна по лінії шляху при впливі морського хвилювання за характеристиками суднових установ за окремими критеріями, які стосуються: якості функціонування (точність, швидкодія та інші); потужності силових установок та чутливості елементів даних суднових систем; надійність роботи енергетичних установок; якість експлуатації суднових елементів та систем, що стосується силових установок та їх автоматизації та інші.

Розглянемо більш детальніше їх для опису та проведення оцінювання впливу під час застосування методів статистики які пов'язані з особливостями функціонування суднових систем керування.

Дослідження що проведені $[4,6]$ показали, що найбільш прийнятними моделями $\epsilon$ моделі строго структуровані, які мають складний покроковий механізм обчислювання даних з можливістю аналізу інформації. Таким чином, можливо сформувати імітаційну модель, яка повинна бути послідовна за виконанням різних етапів, що дозволить провести оцінку отриманих даних (або циркулюючої) в суднових енергетичних система в умовах впливу морської поверхні (рис. 2.). 


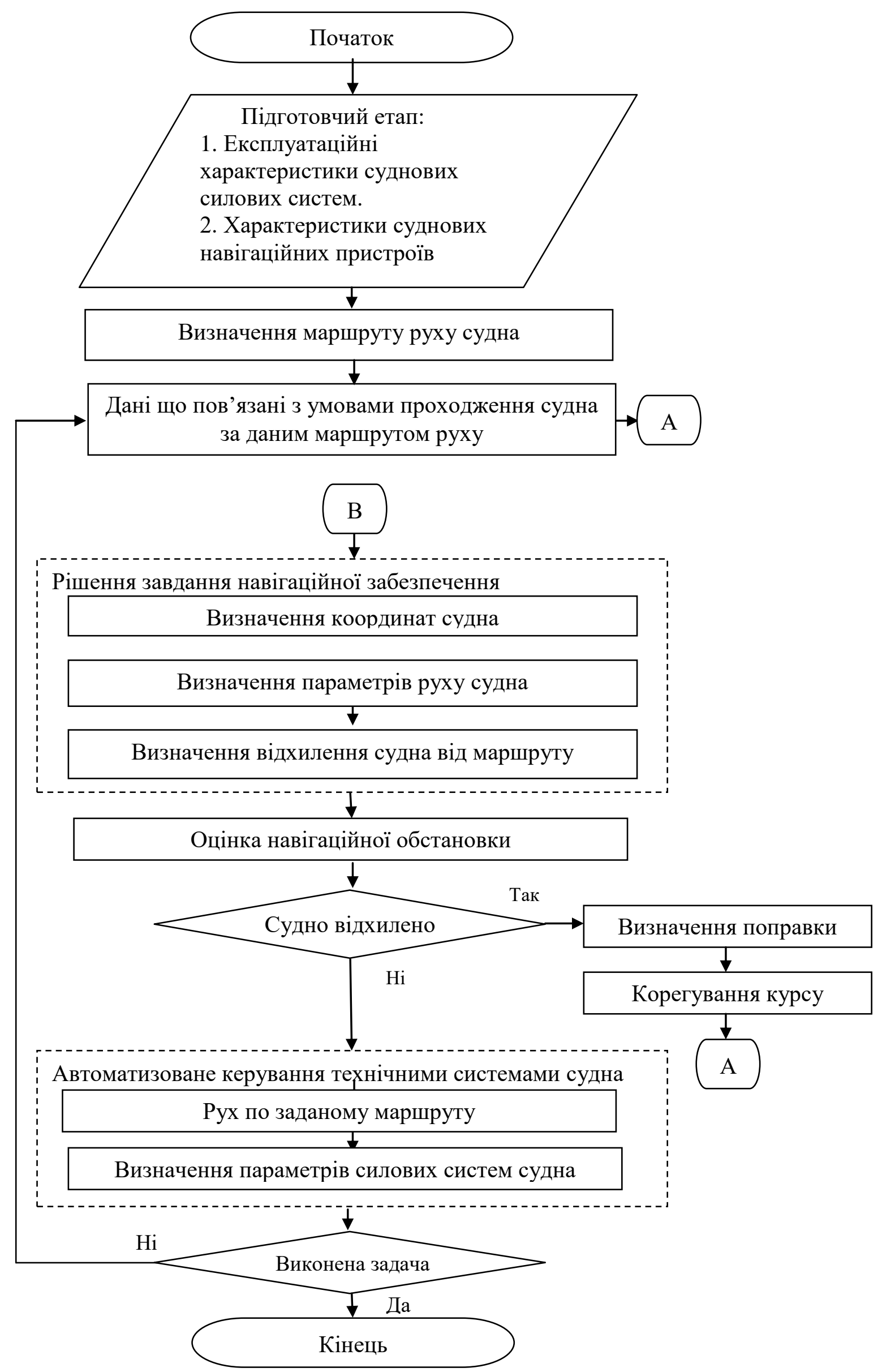

Рисунок 2 - Блок-схема алгоритму функціонування суднових систем 
На заключному етапі імітаційної моделі необхідно провести порівняльну оцінку отриманих результатів з теоретичними даними. В даному випадку необхідно розробити та запропонувати такий математичний апарат який буде здійснювати оцінку функціонального стану як навігаційної обстановки так і надавати дані якості зміни параметрів функціонування суднових силових систем, що будуть характеризувати якість за обраним критерієм для використання даної моделі $[4,6,7]$.

Висновки. На сьогоднішній день використання математичних моделей відкрили можливість на етапах експериментальних досліджень отримати результаті поведінки складних систем їх характеристики, а також можливості в складних умовах та властивості. В статті розроблена та запропонована модель керування рухом судна. Особливістю запропонованої моделі $є$ іiї розрахункова частина в якої здійснюються розрахунки: міста розташування судна; умов експлуатації та застосування суднових систем; визначення впливу морської поверхні на судно; а також обчислювання руху судна по заданому маршруту. Використання даних модулів при їх впливі друг на друга підвищує адекватність та достовірність отриманих результатів. Таким чином, в результаті використання даної моделі можливо отримати результати обчислень що пов'язані як залежностями характеристик від енергетичних установок, так і суднових навігаційних пристроїв в умовах впливу морської поверхні та метеоумов під час керування судном по заданому маршруту.

\section{ЛIТЕРАТУРА}

1. Вагущенко Л.Л. Системы автоматического управления движением судна // Л.Л. Вагущенко, Н.Н. Цымбал. - Одесса: Фенікс, 2007. - 328 с.

2. Вагущенко Л.Л. Современные информационные технологии в судовождении / Л.Л. Вагущенко - Одесса: ОНМА, 2013. - 135 с.

3. Пятаков Э.Н. Электронная навигация и картография / Э.Н. Пятаков. - Херсон: Гринь Д.С., 2017. - 336 с.

4. Современные информационные технологии обеспечения безопасности судноходства и их комплексное использование / В.Е. Леонов, В.И. Дмитриев, О.М. Безбах, А.А. Гуров, В.Б. Сыс, В.Ф. Ходаковский // под ред. Леонова В.Е. Херсон: ИЦ ХГМА, 2014. - 324 с.

5. Власов К.П. Теория автоматического управления / К.П. Власов. - Харьков: Изд-во Гуманитарный центр, 2007. - 526 с.

6. Неймарк Ю.И. Динамические модели теории управления / Ю.И.Неймарк, Н.Я. Коган, В.П. Савельев - М.: Наука, 1985. - 400 с.

7. Імітаційне моделювання систем та процесів: Електронне навчальне видання. Конспект лекцій / В. Б. Неруш, В. В. Курдеча. - К.: НН ІТС НТУУ «КПІ», 2012. $115 \mathrm{c}$.

\section{Бажак О.В., Трофименко И.В., Бойко А.Д. СИНТЕЗ МОДЕЛИ И АЛГОРИТМЫ ПРОЦЕССА УПРАВЛЕНИЯ ДВИЖЕНИЕМ СУДНА}

В статье разработана модель системы управления судном. Особенностью данной модели является взаимосвязь судовых навигационных устройств с энергетическими системами судна. Использование данной модели позволяет изучить и исследовать качественные показатели судна и выявить зависимости влияния их характеристик на качество управления судна.

Также в статье приведены алгоритмические решения системы управления судном и освещаются положительные и отрицательные свойства их использования.

Для исследования движения судна обычно применяются динамические модели с оптимизацией управляющих воздействий. При этом в качестве модели динамике 34 
пространственного состояния можно использовать модель Пуанкоре, а для частичного решения систем уравнений данных моделей можно использовать статистические методы. Это связано с тем, что, аналитические решения находятся только в немногих случаях.

Таким образом, возникает необходимость разработки новых моделей движения судна по заданному маршруту и его управления в сложной динамической обстановке.

Поэтому целью данной статьи является разработка модели системы управления судном с возможностью освещения логических связей для повышения эффективности судовождения во время его эксплуатации в сложных условиях для обеспечения безопасности управления судна.

Ключевые слова: автоматизированная система управления, навигационные устройства, судовождения, управления судном, энергетические системы.

\section{Bazhak O.V., Trofimenko I.V., Boyko A.D.}

\section{SYNTHESIS OF THE MODEL AND ALGORITHMS OF THE VESSEL MOTION CONTROL}

The model of ship control systems is developed in the article. A feature of this model is the relationship of ship navigation devices with the ship's power systems. The use of this model allows to study and investigate the quality of the vessel and to identify the dependences of the impact of their characteristics on the quality of ship management.

The article also presents algorithmic solutions of the ship control system and highlights the positive and negative properties of their use.

Dynamic models with optimization of control effects are usually used to study the movement of the vessel. In this case, as a model of the dynamics of the spatial state, you can use the Poincore model, and to partially solve the systems of equations of these models, you can use statistical methods. This is due to the fact that analytical solutions are found in only a few cases.

Thus, there is a need to develop new models of vessel movement along a given route and its management in a complex dynamic environment.

Therefore, the aim of this article is to develop a model of a ship management system with the ability to highlight logical connections to improve the efficiency of navigation during its operation in difficult conditions to ensure the safety of ship management.

Key words: automated control system, navigation devices, navigation, ship control, power systems 